\title{
RHINOLOGY
}

\section{Approach to the correction of drooping tip: common problems and solutions}

\author{
Approccio alla correzione della punta cadente: problemi comuni e soluzioni \\ P.G. GIACOMINI', S. RUBINO ${ }^{1}$, S. MOCELLA², M. PASCALI ${ }^{3}$, S. DI GIROLAMO'1 \\ ${ }^{1}$ Department of Otolaryngology, University of Rome "Tor Vergata", Italy; ${ }^{2}$ Department of Otorhinolaryngology, \\ Bussolengo Hospital, Italy; ${ }^{3}$ Department of Plastic Surgery, University of Rome "Tor Vergata", Italy
}

\section{SUMMARY}

The drooping tip deformity is both a bothersome aesthetic feature and functional impairment of the nose. Both static and dynamic factors may affect tip appearance and it seems logical to take into account these factors when planning correction of drooping tip. Many studies have examined this topic, but its treatment remains controversial. In order to make nasal tip surgery successful, it is useful to identify the keystone anatomical characteristics of the tip itself. Naso-labial angle, nostril axis, tip rotation angle according to Frankfort plane and columellar-facial angle may be measured to assess nasal tip position. The present study focuses on the authors' personal experience on the key anatomic changes of the nose that deserve correction and on the main surgical steps needed to achieve consistent results when dealing with a drooping tip. Pre- and post-operative nasal tip rotation and projection were studied. Correction of the drooping tip was accomplished by an open or closed septorhinoplasty approach according to patient's needs. The surgical techniques mostly employed for tip repositioning was septum straightening (41/41) and tongue-in-groove (36/41 cases) (87.8\%). A columellar strut was used in 8/41 (19.51\%) cases. LLC cephalic resection was applied in 29/41 patients (70.73\%), LLC re-orienting sutures were made in 18/41 cases (43.9\%) and lateral crural overlay was needed in $2 / 41(4.8 \%)$. The key anatomic changes of the nose that deserve correction and the surgical steps needed to ease the often intriguing pre-operative decision-making process are reviewed.

KEY WORDS: Drooping tip • Rhinoplasty • Tip surgery $\bullet$ Tip measurements

\section{RIASSUNTO}

La punta cadente è una fastidiosa deformità estetica e funzionale del naso. L'aspetto della punta è influenzato da aspetti sia statici che dinamici. Per questo motivo, appare logico tenere in considerazione questi fattori nel pianificare la correzione chirurgica di questa deformità. Molti studi hanno affrontato questo argomento, ma il trattamento resta controverso. Per rendere efficace la chirurgia della punta appare indispensabile identificare le caratteristiche anatomiche fondamentali della punta stessa. Diversi angoli e misure possono essere calcolati per definire la posizione della punta tra cui: l'angolo nasolabiale, l'asse della narice, l'angolo di rotazione della punta in rapporto al piano di Francoforte, l'angolo columellare-facciale. L'obiettivo di questo studio è focalizzare l'attenzione sulla nostra esperienza personale sulle alterazioni anatomiche del naso che meritano una correzione e sulle procedure chirurgiche necessarie per ottenere risultati soddisfacenti nel trattamento della punta cadente. Nel presente studio sono stati presi in considerazione la proiezione e la rotazione della punta pre e post-operatorie. La correzione della punta cadente è stata ottenuta mediante settorinoplastica aperta o chiusa a seconda dei casi. La tecnica prevalentemente usata per riposizionare la punta è risultata essere il raddrizzamento del setto (41/41 casi) e la tecnica Tongue-in-groove (36/41 casi) (87,6\%). Lo strut columellare è stato impiegato in 8/41 pazienti (19,51\%). Resezioni cefaliche delle cartilagini alari sono state applicate in $29 / 41$ pazienti $(70,73 \%)$. Suture per ri-orientare le cartilagini alari sono state impiegate in $18 / 41$ casi (43,9\%). Il Lateral crural overlay è stato necessario in $2 / 41$ casi $(4,8 \%)$. Il presente articolo rivaluta le principali varianti anatomiche del naso che meritano correzione e le tecniche chirurgiche utilizzabili per semplificare il processo decisionale preoperatorio.

PAROLE CHIAVE: Rinoplastica $\bullet$ Punta cadente $\bullet$ Chirurgia della punta $\bullet$ Misurazioni della punta

Acta Otorhinolaryngol Ital 2017;37:295-302

\section{Introduction}

The drooping tip deformity is both a bothersome aesthetic feature and functional impairment of the nose. Aesthetically, the distally displaced tip gives an aged and unpleasant look, and sometimes the tip also descends or "plunges" during smiling. Functionally these conditions may affect the nasal patency due to incompetence of the internal nasal valve that is stenotised by tip malposition. Both static and dynamic factors may affect tip appearance: the former linked to the malposition and incorrect shape of the nasal septum, upper and lower lateral cartilages and the ligaments in between, the latter derive from the dynamic action of the depressor septi nasi and levator 
labii superioris alaeque nasi muscles. When dynamic factors are involved drooping of the nasal tip, elevation and shortening of the upper lip, and increased maxillary gingival visibility occur during smiling ${ }^{1}$.

It seems logical to take into account static and dynamic factors along with ancillary causes when planning correction of drooping tip ${ }^{2}$. Many studies have examined this topic, but its treatment remains controversial ${ }^{3}$. In order to make nasal tip surgery successful, we believe that it is useful to identify the key anatomical characteristics of the tip itself.

The method to evaluate tip position is not uniform across different studies. Naso-labial angle, nostril axis and columellar-facial angle may be measured to assess nasal tip position. Although not entirely accurate, the nasolabial angle is often considered synonymous with nasal tip rotation. Patients with drooping tip have a nasolabial angle that is sharper than expected. The columellar-facial angle seems most likely to yield consistent measurements of nasal tip rotation ${ }^{4}$. More recently three angles were measured on lateral view (tip angle, nasolabial angle, and columella inclination angle) and changes in static and smiling positions were also compared ${ }^{5}$.

The aim of the present study is to focus on the personal experience regarding the key anatomic changes of the nose that deserve correction and on the main surgical steps needed to achieve consistent results when dealing with a drooping tip.

\section{Materials and methods}

From a consecutive series of primary septorhinoplasties performed from January $1^{\text {st }}, 2010$ to December $31^{\text {st, }} 2012$ in Caucasian patients, we selected 41 cases presenting a drooping tip. A drooping tip was diagnosed in case of a nasolabial angle less than $90-95^{\circ}$ in men and less than $100-105^{\circ}$ in women.

We retrospectively analysed photographs of 17 men and 24 women (21-57 years of age) submitted to septorhinoplasty. Exclusion criteria consisted of a history of facial surgery or injury and an abnormal facial expression.

Photographs were obtained according to techniques of standardised clinical photography: hair covering the face, hair bands, hairpins, and eyeglasses were removed, a constant brightness and exposure were used. The patient was placed on fabric background. The distance between the patient and the camera was fixed at $50 \mathrm{~cm}$. The subject was also instructed to keep his or her jaw in a relaxed position and eyes level with the horizontal line. Lateral photographs with the Frankfort horizontal plane parallel to the ground were taken. We used a commercially available computer program (Golden Ratio software ver. 3.1, copyright by Markus Welz, Germany) for photograph measurements. Measurements were performed by two experienced examiners, and the mean was calculated.

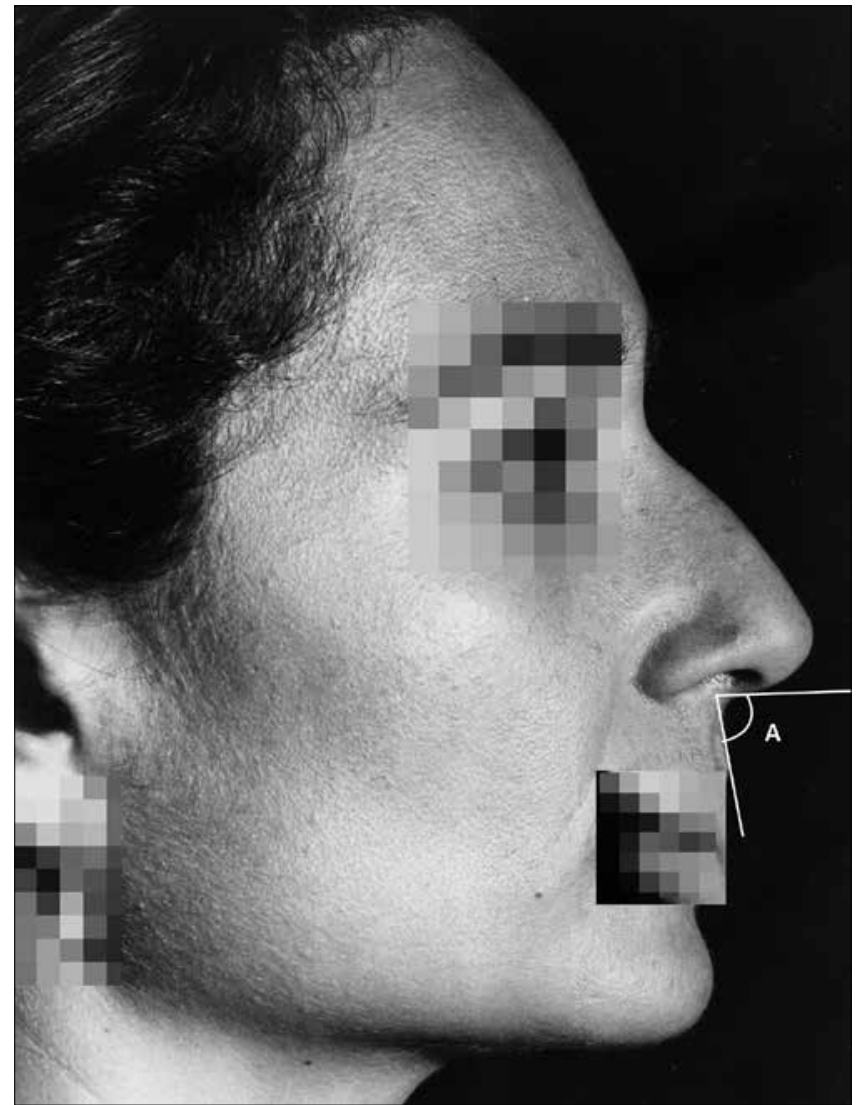

Fig. 1. A) Naso-labial angle.

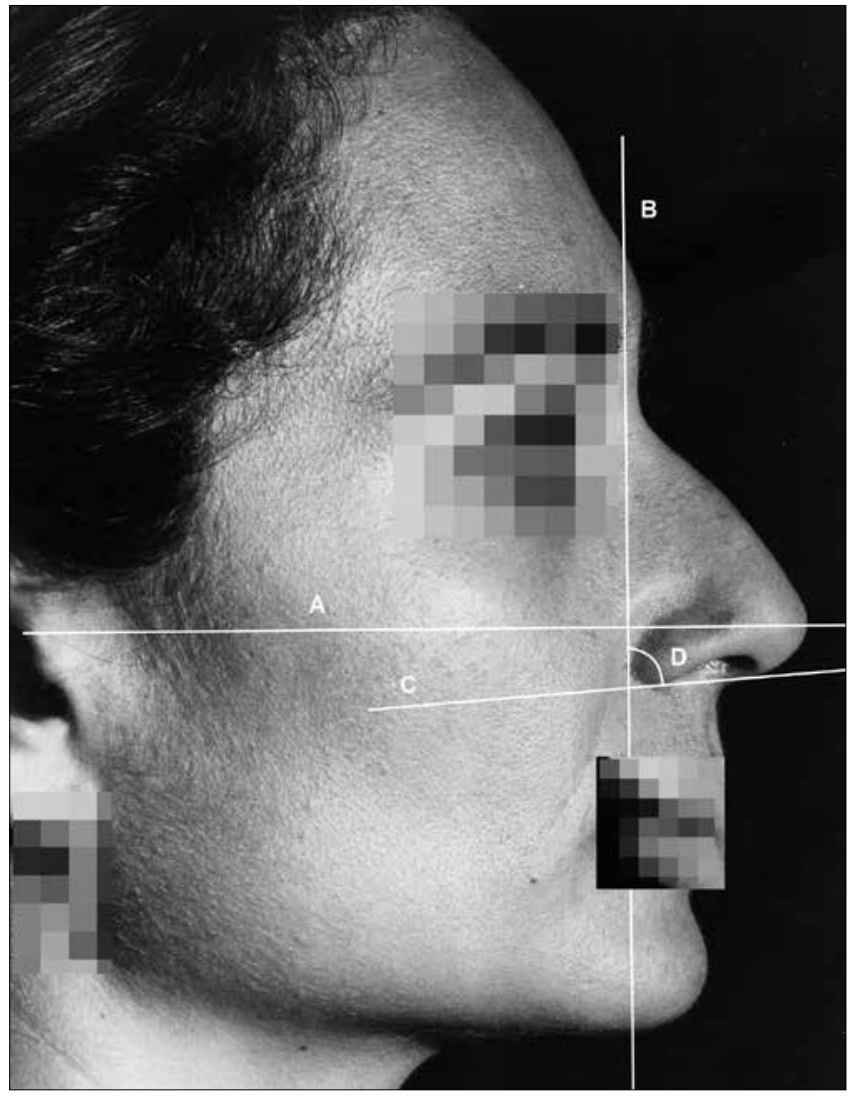

Fig. 2. A) Frankfort horizontal plane; B) Line perpendicular to Frankfort plane; C) line parallel to columella; D) columellar-facial angle. 
Pre- and post-operative nasal tip rotation and projection were studied. Tip rotation was evaluated by measuring the nasolabial angle (Fig. 1): on profile view it was assessed as the angle between the upper lip and the columella. Rotation of the nose refers to nasal tip position relative to an imaginary arc on profile view of the face. A normal nasolabial angle in a male is $90-95^{\circ}$, while normal in a female it is $100-105^{\circ}$. Alternatively, nasal tip rotation was based on use of what is termed the Frankfort horizontal plane, by a line drawn from the lower rim of the bony eye socket toward the ear canal. A second line was drawn in parallel to the columella. The angle created by the intersection of these two lines was considered a reliable measure of the nasal tip rotation. A range of $0-15^{\circ}$ in males and $15-30^{\circ}$ in females is considered ideal. A third angle was also explored: it was drawn by the line parallel to the columella intersected with the alar line, which is a line running perpendicular to the Frankfort plane. The alar line runs through the alar-facial crease, which is where the nasal base attaches to the cheek. (Fig. 2) The latter was developed to avoid the need of measuring a pre-operative "negative" angle between the columella and the Frankfort plane (due the preoperative plunging of the tip) and a "positive" post-operative angle (Figs. 3, 4).

Nasal tip projection was assessed by the Goode method. A measurement was taken from the nasal tip to the alar line ("A") and compared to the distance from the nasal tip to the nasal starting point ("B"). The ratio of "A" to " $\mathrm{B}$ " is a measure of tip projection and should ideally be 0.55 0.60 in most patients. A lower ratio was considered as an underprojected tip.

Malposition and incorrect shape of the nasal septum, upper and lower lateral cartilages, and the dynamic action of the depressor septi nasi and levator labii superioris alaeque nasi muscles, were checked to assess the surgical steps needed for tip correction. Changes of tip, subnasale and alar crease were also noted in both static and smiling positions.

Correction of drooping tip was accomplished by closed or open septorhinoplasty approach according to the needs: inter-cartilaginous incision was used for access to the nasal dorsum and full transfix incision of the membranous septum for septal correction in closed approaches, alternatively inverted $\mathrm{V}$ columellar incision prolonged as marginal incision in open approaches were employed. Cephalic alar cartilages resection and their re-orientation by sutures or lateral crural interruption and overlapping were performed ${ }^{6}$ (as necessary according to the pre-intraoperative evaluation of LLC length). Correction of the septal inferior border length and shape were obtained by careful wedge resection of the same in a triangular, anteriorly-based fashion, taking care not to de-project the tip. Before final suturing, the redundant vestibular skin and mucosa, when present, were excised to avoid nasal valve obstruction.

In case of dynamic nasal tip changes during smiling for

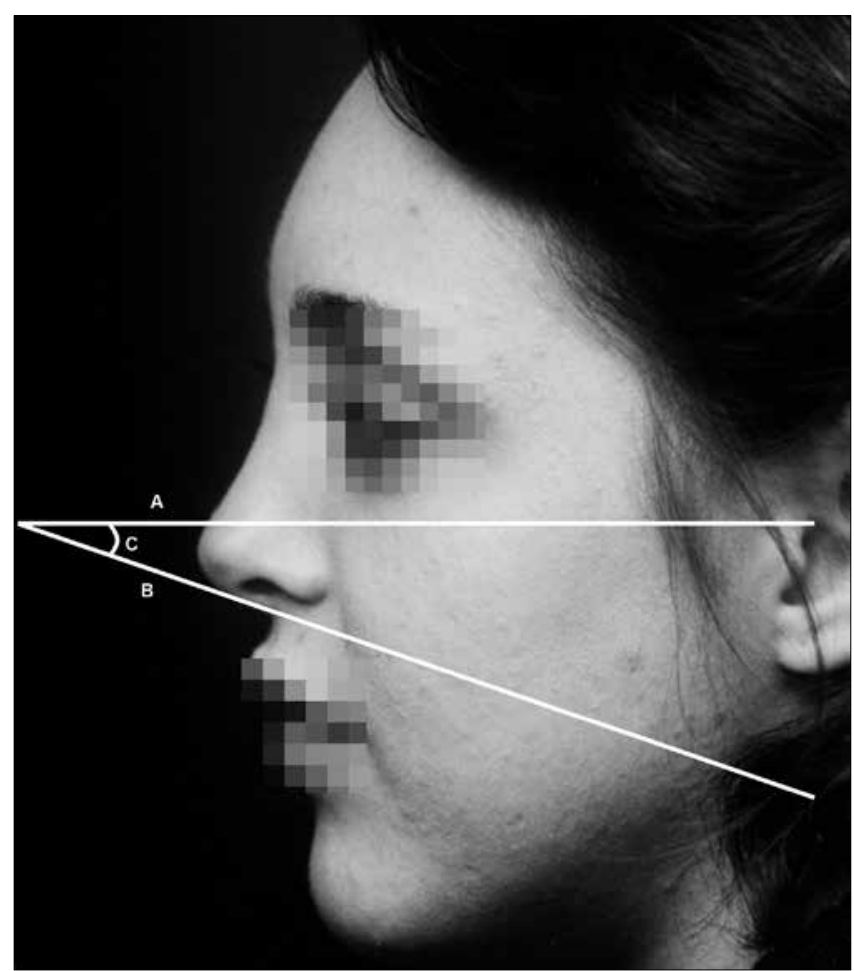

Fig. 3. A) Frankfort horizontal plane; B) line parallel to columella; C) Tip rotation angle.

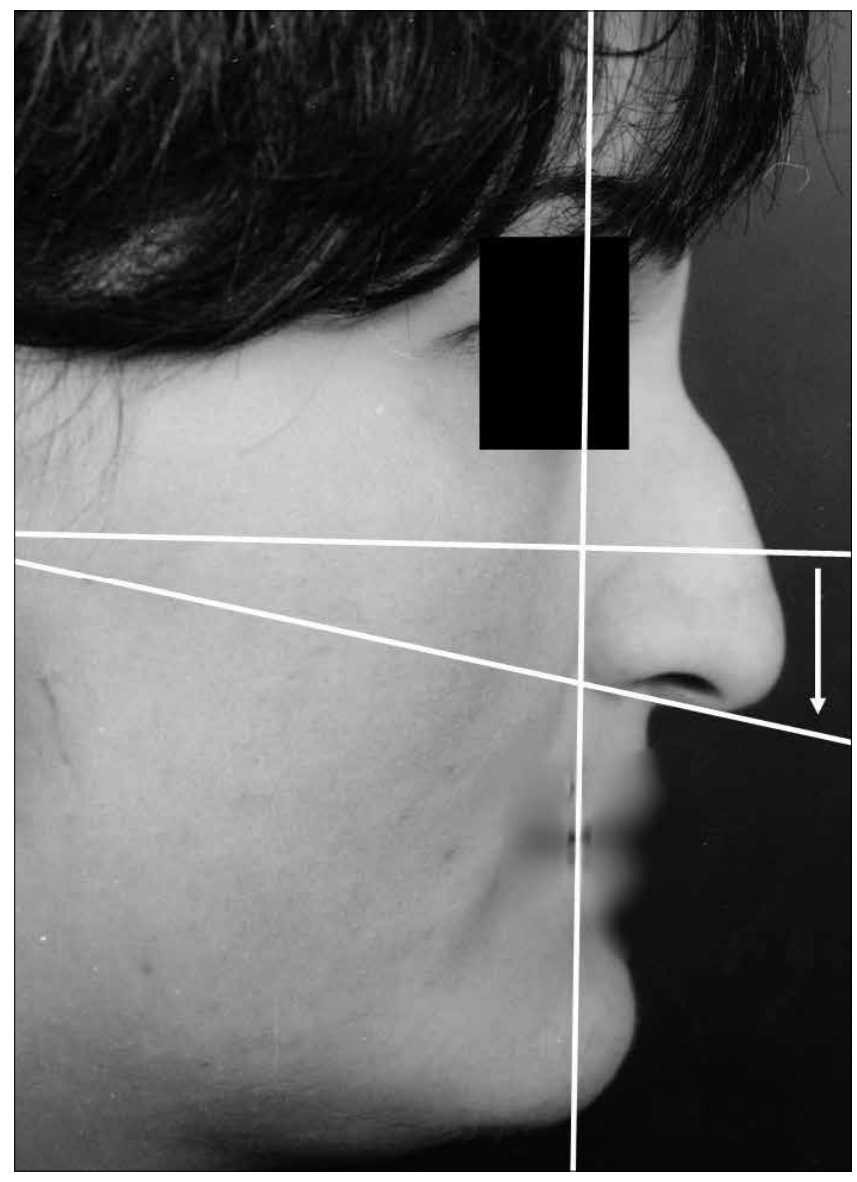

Fig. 4. In drooping tips the Frankfort plane and the line parallel to columella do not encounter between themselves, so that it is not possible to correctly calculate the tip rotation with this method. 
depressor septi muscle action, muscle excision just below the footplates of the medial crura when felt necessary was carried out. Counteraction of the residual depressor septi muscle action, as well as the scar contracture pulling down the newly positioned tip, was always considered mandatory: either a strong columellar strut graft placed between the medial crura or a Tongue-in-Groove ${ }^{7}$ fixation of the medial crura to the caudal septum, or both, were applied. Correction of the residual (if present) columellar-labial acute angle was achieved using a columellar strut graft extending to the nasal spine and/or by plumping graft of the pre-spinal area. All grafting material was autologous septal cartilage.

\section{Results}

The surgical technique mostly employed for tip repositioning was septum straightening and shortening (41/41) and Tongue-in-groove (36/41 cases) (87.8\%) (Figs. 5-6). A columellar strut was used in $8 / 41$ cases $(19.51 \%)$ (Figs. 7, 8). LLC cephalic resection was applied in 29/41 patients $(70.73 \%)$ and LLC re-orienting sutures were made in $18 / 41$ cases $(43.9 \%)$. Lateral crural overlay was needed in $2 / 41$ (4.8\%) to correct excessive LLC length (Figs. 9, 10).

Both hyper- or normo-dynamic nasal tip ptosis were corrected in all patients as shown by the nasal angles pre- and post-operative measures reported in Tables I-III: post-operative angles were reported as matching the value considered as "ideal" or improved, but not completely corresponding to

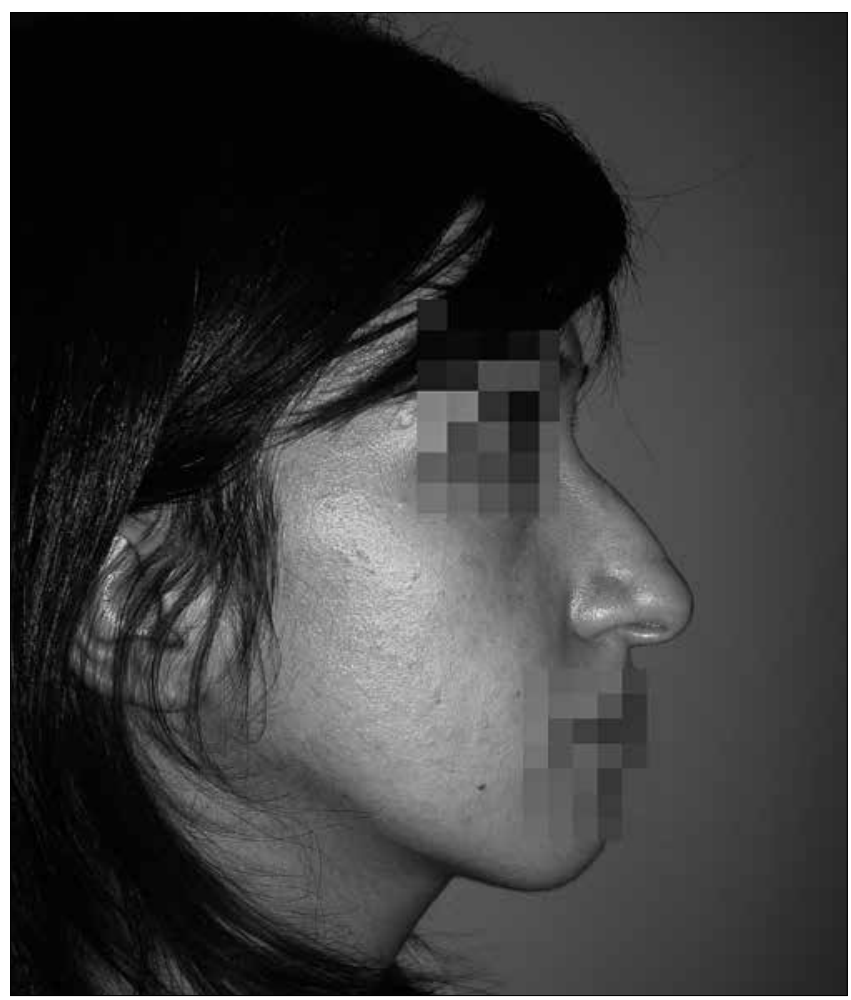

Fig. 5. Tongue-in-Groove (pre-operative image).
Table I. Pre- and post-operative results.

\begin{tabular}{lcc} 
Naso-labial angle & Pre-operative & Post-operative \\
Mean $+\mathrm{SD}$ & $77.338 \pm 15.094$ & $93.924 \pm 8.954$ * \\
Normal value $(\mathrm{n} / \mathrm{N})$ & $0 / 41$ & $19 / 41$ \\
Improved tip position $(\mathrm{n} / \mathrm{N})$ & - & $22 / 41$ \\
\hline$p<0.001$ & &
\end{tabular}

Table II. Pre- and post-operative results.

\begin{tabular}{lcc}
\hline Columellar-facial angle & Pre-operative & Post-operative \\
Mean + SD & $92.406 \pm 4.552$ & $81.95 \pm 5.414^{*}$ \\
Normal value $(\mathrm{n} / \mathrm{N})$ & $2 / 41$ & $21 / 41$ \\
Improved tip position $(\mathrm{n} / \mathrm{N})$ & - & $20 / 41$ \\
\hline$p<0.001$ & &
\end{tabular}

Table III. Pre- and post-operative results.

\begin{tabular}{lcc}
\hline Tip rotation angle & Pre-operative & Post-operative \\
Mean $+\mathrm{SD}$ & $-2.357 \pm 4.579$ & $8.051 \pm 5.414^{*}$ \\
Normal value $(\mathrm{n} / \mathrm{N})$ & $2 / 41$ & $21 / 41$ \\
Improved tip position $(\mathrm{n} / \mathrm{N})$ & - & $20 / 41$ \\
\hline
\end{tabular}

$p<0.001$

the normal value. For the naso-labial angle and for tip rotation, calculated according to the Frankfort plane, an increase in the angle value was considered as improvement; on the contrary, a decrease was the goal on the columellar-facial angle. No major or late complications (36 months follow-up)

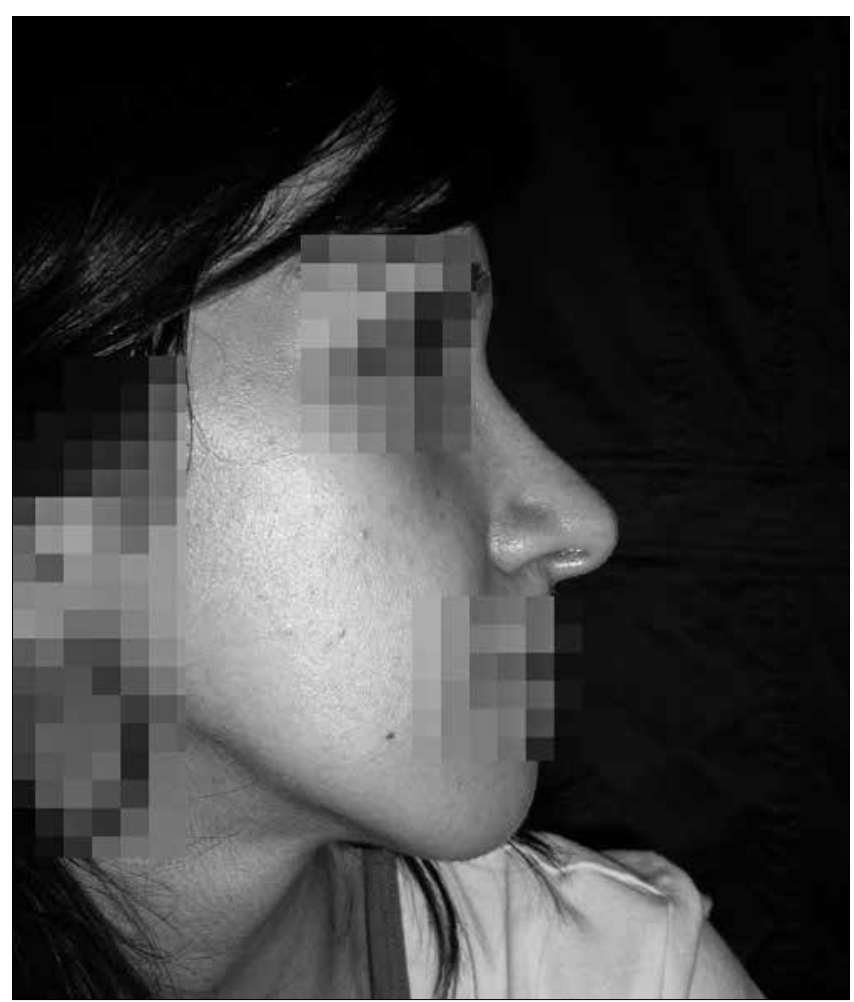

Fig. 6. Tongue-in-Groove (post-operative image). 


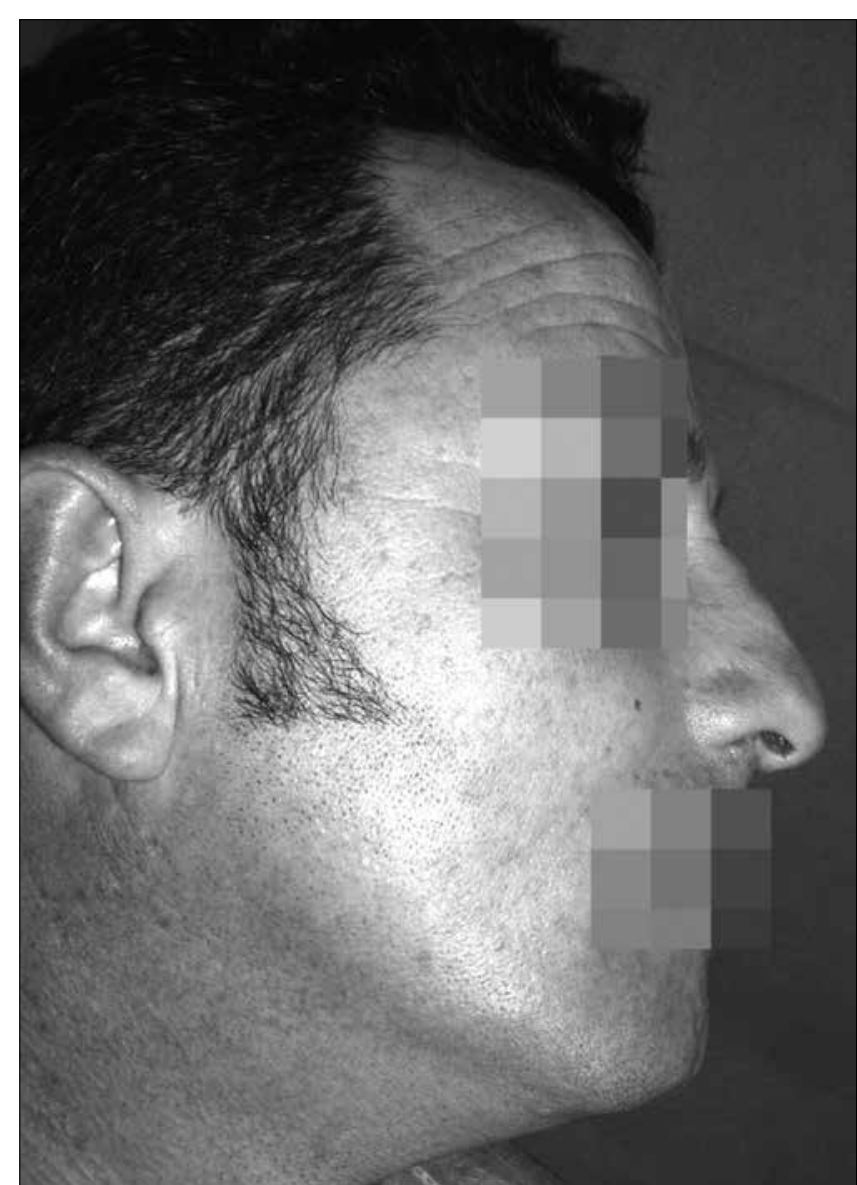

Fig. 7. Columellar strut (pre-operative image).

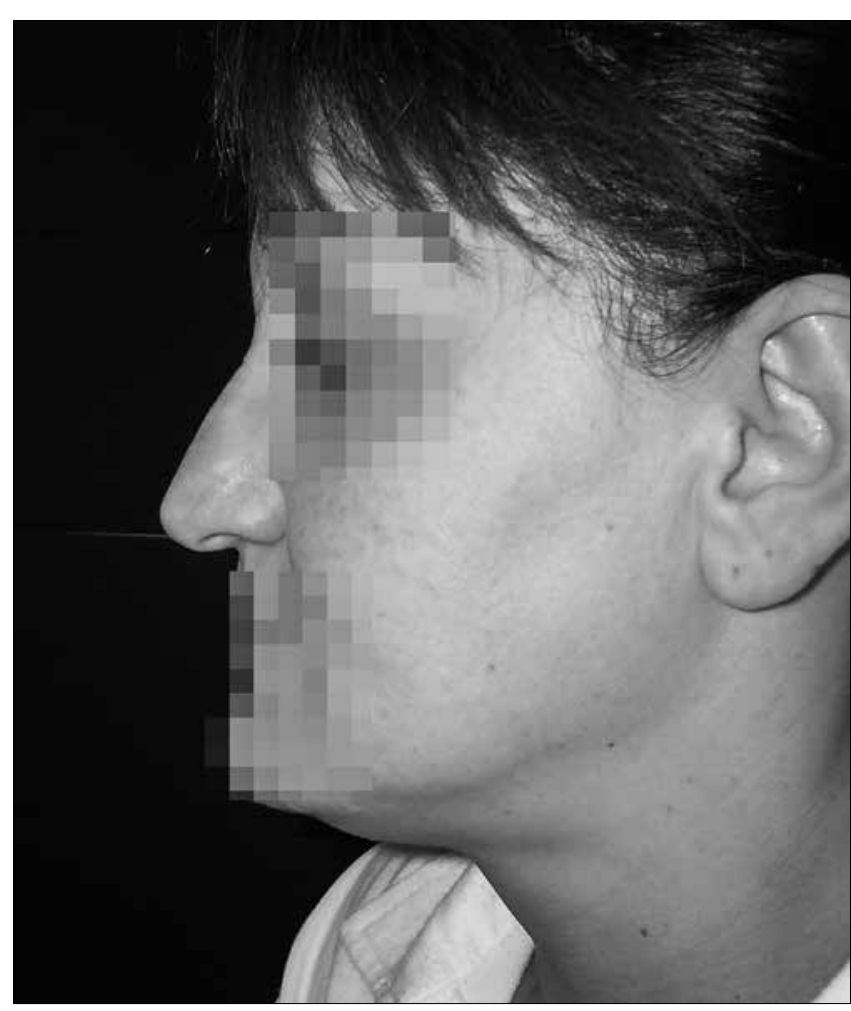

Fig. 9. Lateral crural overlay (pre-operative image).

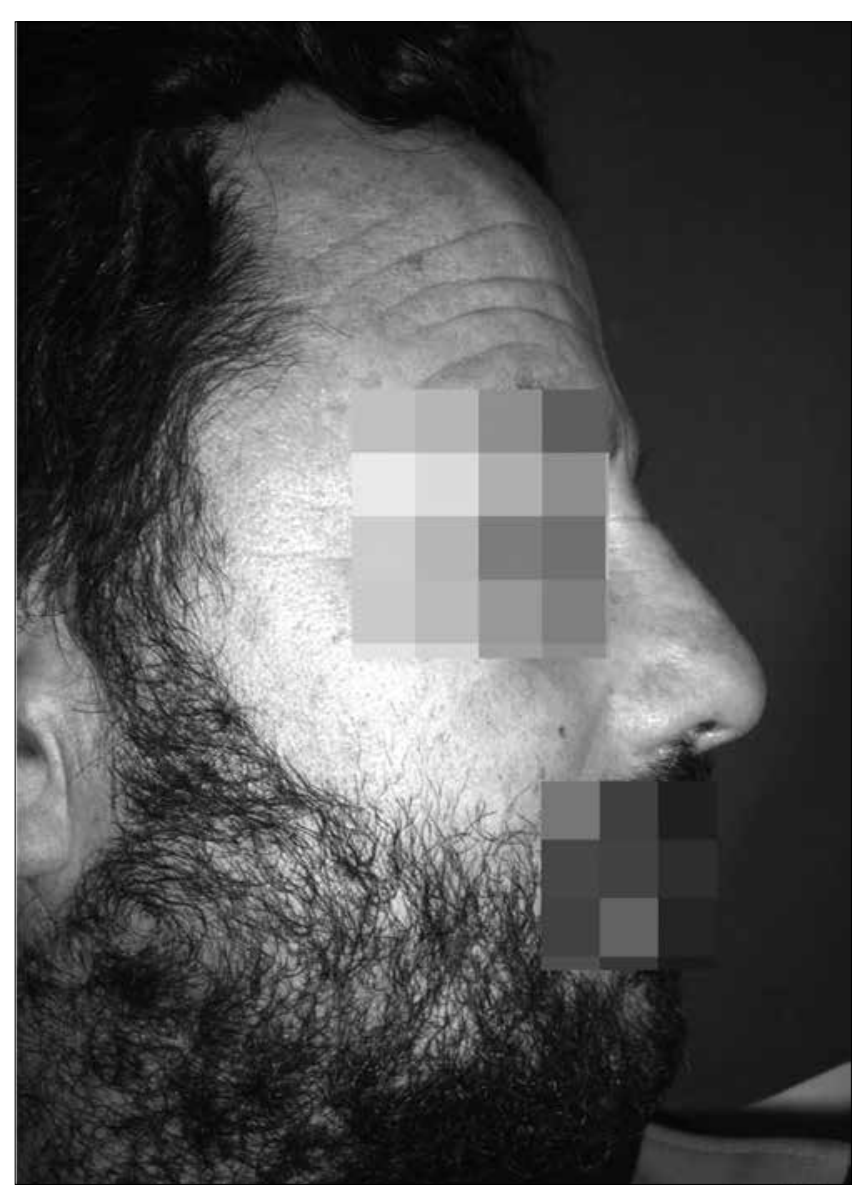

Fig. 8. Columellar strut (post-operative image).

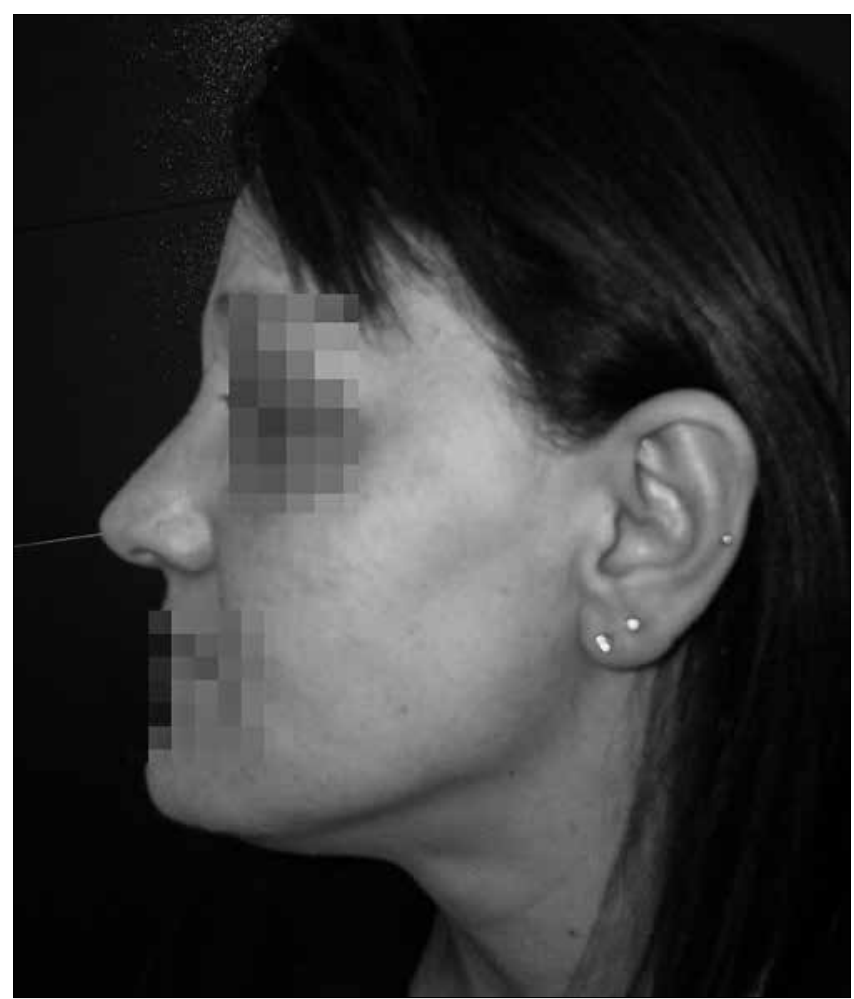

Fig. 10. Lateral crural overlay (post-operative image). 
Table IV. Pre- and post-operative results.

\begin{tabular}{lcc} 
Tip projection (Goode Ratio) & Pre-operative & Post-operative \\
Mean + SD & $0.638 \pm 0.054$ & $0.647 \pm 0.061$ (n.S.) \\
Normal value (n/N) & $13 / 41$ & $15 / 41$ \\
Underprojection (n/N) & $1 / 41$ & $0 / 41$ \\
Overprojection $(\mathrm{n} / \mathrm{N})$ & $27 / 41$ & $26 / 41$ \\
\hline
\end{tabular}

Table V. Major and minor nasal tip supporting mechanisms (from Sajjadian, Guyuron, $2009^{10}$, mod.).

\begin{tabular}{ll}
$\begin{array}{l}\text { Major tip supporting } \\
\text { mechanisms }\end{array}$ & Minor tip supporting mechanisms \\
$\begin{array}{l}\text { Shape, resilience and size of the } \\
\text { lower lateral cartilage }\end{array}$ & $\begin{array}{l}\text { Attachment of the paired domes, } \\
\text { nasal spine and membranous septum }\end{array}$ \\
$\begin{array}{l}\text { Attachment between the septum } \\
\text { and upper lateral cartilage }\end{array}$ & $\begin{array}{l}\text { Attachments of the lateral crura to } \\
\text { the piriform aperture }\end{array}$ \\
$\begin{array}{l}\text { Attachment between the septum } \\
\text { and medial crus }\end{array}$ & \\
Anterocaudal septum & \\
\hline
\end{tabular}

were recorded. Minor complications were rarely observed (two cases of minor infection around the stitches in the columellar area, quickly resolved without consequences) in the early postoperative period. Resection of the depressor septi also corrected the upper lip length and gingival show during smiling in 4/41 cases. The columellar width was not grossly reduced by depressor septi resection or increased by columellar strut grafting (8 cases). Residual correction of the columellar-labial junction when needed (8/41 patients) was always achieved by pre-spinal plumping graft positioning. Tip projection analysis (Table IV) revealed that preoperatively there were $13 / 41$ patients $(31.7 \%)$ showing a normal projection according to Goode's ratio, with 1/41 underprojecting tip (2.4\%) and 27/41 overprojecting tip (65.8\%). After surgery there were no patients with underprojection, while there were $26 / 41$ overprojecting (63.4\%) and 15/41 (36.6\%) in the normal range.

\section{Discussion}

Patients undergoing primary rhinoplasty have been reported to exhibit, in the majority of cases $(61 \%)$, a need for increased tip support and to a lesser degree (46\%) the need for correction of alar cartilage malposition ${ }^{8}$. In a selected subgroup of cases such as patients affected by drooping tip these percentages are expected to be higher and thus the need for significant correction of the tip itself, even if this correction is somewhat controversial 9. There are several tip supporting mechanisms in the nose (Table V) ${ }^{10}$. Due to the multifactorial causes of drooping tip, the surgical strategy of intervention must take into account different manoeuvers aimed to correct the static and dynamic alterations that may be present in each single case. Straightforward evaluation of the patient's anatomy will suggest the surgical steps to be applied. One key step is re-establishment of a correct tip position in accordance with its length, projection and shape obtained by framework modifications.

According to the tripod theory, pulling vectors act on lateral LLC crura suspending the tip and pushing forces act on the medial LLC supporting the tip itself: their concurrent action determines the tip position ${ }^{11}$. Cues then arise to determine whether improving the pushing effect or enhancing the pulling forces would be more efficient to correct the drooping tip to gain adequate and stable upward rotation.

Constantian (2004) reported inadequate tip projection and convex lateral crura be more common among patients with malpositioned lateral crura $(78 \%$ and $61 \%$, respectively) than in patients with orthotopic lateral crura $(57 \%$ and $20 \%$, respectively). In our Caucasian drooping tip patients, the hypo-projecting tip associated with arched, convex nostrils accounted for a minority of cases, while Goode's Ratio showed mostly overprojecting tips.

In Asian patients, Park (2014) recently highlighted four relevant factors in this surgery: first of all, the alar cartilage or nasal septal cartilage problem should be corrected. Alar cartilage shape and orientation must therefore be revised and properly restored to give the tip a good projection and position: re-shaping/re-orienting of the lower lateral cartilages by cephalic resection and stitching is therefore advised. Additionally, correction of the septal inferior border length and shape must be achieved to straighten the nostril profile and let the tip lift upwards. Patients with true ptosis of the tip for excessive nasal length will benefit from septum antero-inferior shortening by cartilage and membranous septum removal, while cases with tip over-projection may need lateral crura shortening if they are too long. In this case, excessive shortening must be avoided to skip tip de-projection ${ }^{10}$. Among the former factors, the hypoprojection correction seems secondary in our series of Caucasians.

Once reshaped, the framework itself needs to be reinforced in order to warrant a persistent and adequate tip projection that may be jeopardised by some residual downward pulling of the tip exerted by the scar contracture over time and by the residual muscular activity of the depressor septi. Columellar strut, batten grafts and the tongue-in-groove technique all seem valuable for this goal ${ }^{812}$.

In our experience, the simplest and most effective way to re-position and maintain the correct tip rotation is to restore the pushing effect of the medial crura on the nasal tip itself.

The tongue-in-groove technique associated with septum antero-inferior realigning and wedge shortening is a simple and reliable way to gain upward rotation of the tip while maintaining adequate projection; it was successfully employed in 36/41 (87.8\%) cases. A columellar strut was used in only 8/41 (19.5\%) cases: specifically, in one case of un- 
derprojection associated with drooping tip, one case of open approach and whenever it was felt necessary that stronger support for the tip was needed. The upward pull exerted by LLC lateral crura was reinforced by cephalic resection with/without stitching of the same in 29 cases $(70.7 \%)$, stitching was mainly used for re-shaping purposes; "major" procedures (e.g. LLC lateral crus interruption-resuturing) were needed in only 2 patients $(4.8 \%)$ of the present series of unselected drooping tip cases. Therefore, aggressive procedures on the LLC seem to be reserved to very selected and specific indications: excessively long lateral crura may give rise to an unpleasant "arched" nostril profile when the upward lift of the tip is carried out conservatively without concomitant shortening of the length of the lateral crus. It must also be taken into account that a "plunging tip" may sometimes be due to an optical illusion: during smiling, the real position of the tip is steady, but alar crease and subnasale elevate while the alar rim straightens. Kosins demonstrated that objectively the tip moves less than $1 \mathrm{~mm}$ and less than $1^{\circ} 5$. "...When a person smiles, the functional unit is activated by a combination of two forces acting simultaneously in opposite directions that rotate the tip caudally and elevate the nasal base. The levator moves the alar base upward and the depressor pulls the tip caudally..." 9. The depressor septi muscle originates from the alveolar bone and inserts the footplates of the medial crus and caudal septum and interdigitates with the medial fascicles and orbicularis oris ${ }^{3}$. Since the depressor septi is responsible for smiling deformity, correction of the same helps to improve both it and the tip-lip relationship ${ }^{13}$. An intranasal or open approach resection of this muscle has been shown to be effective in correcting a drooping nasal tip because it prevents the inferior pull of the tip during smiling ${ }^{13}$; in our series this was the case in $4 / 41$ patients $(9.7 \%)$. Dissecting free from the accessories and sectioning the muscle and, if necessary, the accessory cartilages of the lower laterals has also been suggested because it benefits the "tense nose" aspect and smiling deformity ${ }^{14}$. Final refining steps include the redundant soft tissues of the nasal vestibule such as the mucosa and submucosa deserve trimming to help prevention of relapses of the falling tip after correction as well as nasal valve obstruction ${ }^{2}$. Plumping grafts in the pre-maxillary area were successfully used in 4/41 (9.7\%) cases to improve the prespinal region projection when an acute naso-labial angle is present, as correction of the columellar base retraction is aesthetically pleasant and helps to support the nasal tip ${ }^{15}$. Our personal experience on the key anatomic changes of the nose that deserve correction and on the main surgical steps needed to achieve consistent results when dealing with a drooping tip have shown that correction of the drooping tip by closed rhinoplasty approach both in primary and revision cases may be achieved in a vast majority of situations. A sequential approach encompasses careful straightening and shortening of the septal anterior-inferior edge and its fixation to the medial LLC crura as pivotal point to warrant stable "pillar" for tip repositioning, concomitant cephalic alar cartilage resection and re-orientation by stitching may ease the tip upward rotation and reinforce tip supporting mechanisms. Dynamic nasal tip changes during smiling for depressor septi hyper-action, if present, can be successfully addressed by muscle excision. Counteraction of the residual depressor septi muscle action and scar contracture need columellar strut grafting if severe underprojection is present or when an open approach is used; alternatively, a Tongue-inGroove fixation of the medial crura in our experience was satisfactorily applied in the majority of cases. We favour the use of this procedure because it is quick, simple and avoids possible complications due to grafting of the columella (i.e. infection, re-absorption, dislocation, extrusion of the strut). Ancillary procedures may refine the results by skin and mucosa trimming and naso-labial angle adjunctive widening by the use of pre-spinal plumping graft. Grafting material can be autologous (e.g. septal cartilage, conchal cartilage, etc.) or alloplastic. Several alloplastic materials have been used in surgery. In general, they shorten the duration of surgery, reduce trauma to the donor region and are readily available. The main drawback is tissue response, which may lead to extrusion and/or poor resistance to infection over time ${ }^{17}$.

Finally, to prevent respiratory problems that can cause dissatisfaction to the patient despite a pleasant aesthetic outcome, inferior turbinoplasty is a simple adjuvant procedure to prevent nasal obstruction after rhinoplasty ${ }^{18}$. In the present series, turbinoplasty by coblation was routinely adopted during septorhinoplasty.

\section{Conclusions}

The present review of our personal experience on the key anatomic changes of the nose that deserve correction and on the main surgical steps needed to achieve consistent correction of the drooping tip highlights the surgical strategies that are reliable and the clinical observations that ease the often intriguing pre-operative decision-making process.

\section{References}

1 Tellioglu AT, Inozu E, Ozakpinar R, et al. Treatment of hyperdynamic nasal tip ptosis in open rhinoplasty: using the anatomic relationship between the depressor septi nasi muscle and the dermocartilaginous ligament. Aesthetic Plast Surg 2012;36:819-26.

2 Park SG, Jeong H, Ye CH. Multifactorial approaches for correction of the drooping tip of a long nose in East asians. Arch Plast Surg 2014;41:630-7.

3 Oh SH, Choi S, Kim DW, et al. Intranasal approach for manipulating the depressor septi nasi. J Craniofac Surg 2012;23:367-9. 
4 Kim DW, Egan KK. Metrics of nasal tip rotation: a comparative analysis. Laryngoscope 2006;116:872-7.

5 Kosins AM, Lambros V, Daniel RK. The plunging tip: illusion and reality. Aesthet Surg J 2014;34:45-55.

6 Boccieri A, Raimondi G. The lateral crural stairstep technique: a modification of the kridel lateral crural overlay technique. Arch Facial Plast Surg 2008;10:56-64.

7 Kridel RW, Scott BA, Foda HM. The tongue-in-groove technique in septorhinoplasty. A 10-year experience. Arch Facial Plast Surg 1999;1:246-56; discussion 257-8.

8 Constantian MB. The two essential elements for planning tip surgery in primary and secondary rhinoplasty: observations based on review of 100 consecutive patients. Plast Reconstr Surg 2004;114:1571-81.

9 Arregui JS, Elejalde MV, Regalado J, et al. Dynamic rhinoplasty for the plunging nasal tip: functional unity of the inferior third of the nose. Plast Reconstr Surg 2000;106:1624-9.

10 Sajjadian A, Guyuron B. An algortithm for treatment of the drooping nose. Aesthetic Surg J 2009;29:199-208.

11 Anderson JR. The dynamic of rhinoplasty. Proceedings of the 9th International Congress of Otorhinolaryngology. Excerpta Medica 1969.
12 Rohrich RJ, Kurkjian TJ, Hoxworth RE, et al. The effect of the columellar strut graft on nasal tip position in primary rhinoplasty. Plast Reconstr Surg 2012;130:926-32.

13 Kalantar-Hormozi A, Beiraghi-Toosi A. Smile analysis in rhinoplasty: a randomized study for comparing resection and transposition of the depressor septi nasi muscle. Plast Reconstr Surg 2014;133:261-8.

14 Barbosa MV, Nahas FX, Ferreira LM. Anatomy of the depressor septi nasi muscle: the basis for correction of deformities of the nosellip junction. Plast Surg Hand Surg 2013;47:102-5.

15 Konior RJ. The droopy nasal tip. Facial Plast Surg Clin North Am 2006;14:291-9.

16 Turner F, Zanaret M, Giovanni A. Evaluation of nasal tip projection. Fr ORL 2007;92:282-7.

17 Sahin E, Cingi C, Eskiizmir G, et al. In vivo tissue response and durability of five novel synthetic polymers in a rabbit model. Acta Otorhinolaryngol Ital 2016;36:101-6.

18 Zojaji R, Keshavarzmanesh M, Bakhshaee M, et al. The effects of inferior turbinoplasty on nasal airflow during cosmetic rhinoplasty. Acta Otorhinolaryngol Ital 2016;36:97-100.

Received: November 9, 2015 - Accepted: July 26, 2016

Address for correspondence: Pier Giorgio Giacomini, Department of Otolaryngology, University of Rome "Tor Vergata", Italy, via Giulio Cesare 14, 00192 Rome, Italy. E-mail: pggiacomini@tiscali.it 